\title{
HUBUNGAN PERILAKU PASIEN DALAM PERAWATAN DIABETES MELITUS DENGAN ULKUS DIABETIKUM PADA PASIEN DIABETES MELITUS DI RUANG RINDU A1 DAN A2 RSUP H. ADAM MALIK MEDAN TAHUN 2015
}

\author{
Suriani Ginting, Wiwik Dwi Arianti \\ Jurusan Keperawatan Poltekkes Kemenkes Medan
}

\begin{abstract}
Abstrak
Diabetes Melitus adalah suatu kumpulan gejala yang timbul pada seseorang yang disebabkan oleh karena adanya peningkatan kadar glukosa darah akibat penurunan sekresi insulin yang progresif dilatarbelakangi oleh resisten insulin dan dapat menimbulkan banyak komplikasi seperti Ulkus Diabetikum jika penderita tidak menjaga pola hidup. Untuk mencegah terjadinya Ulkus Diabetikum dibutuhkan perilaku yang mendukung dari penderita Diabetes Melitus itu sendiri. Penelitian ini bertujuan untuk mengetahui hubungan perilaku pasien dalam perawatan Diabetes Melitus dengan Ulkus Diabetikum pada pasien Diabetes Melitus di Ruang Rindu A1 dan A2 RSUP H. Adam Malik Medan Tahun 2011. Yang menjadi variabel independen adalah Pengetahuan, Sikap, dan Tindakan sedangkan variabel dependen adalah Ulkus Diabteikum. Penelitian ini bersifat Deskriptif Analitik dengan menggunakan desain Cross Sectional yang terdiri dari 33 sampel. Pengumpulan data dilakukan dengan melakukan wawancara melalui kuesioner dan lembar observasi. Adapun analisa data yang digunakan adalah Univariat, Bivariat (Uji Chi Square), dan Multivariat (Uji Regresi Logistik Ganda). Hasil penelitian berdasarkan analisa bivariat yang menggunakan Uji Chi Square menunjukkan adanya hubungan pengetahuan ( $p$ value $=0,040<0,05)$, sikap $(p$ value $=0,027<$ $0,05)$, dan tindakan $(p$ value $=0,024<0,05)$ dengan ulkus diabetikum. Sedangkan berdasarkan analisa multivariat yang menggunakan Uji Regresi Logistik Ganda menunjukkan bahwa variabel tindakan merupakan variabel yang paling dominan berhubungan dengan ulkus diabetikum $(O R=6,024)$. Dengan demikian disarankan kepada pasien untuk mempertahankan perilaku yang mendukung perawatan Diabetes Melitus supaya kejadian Ulkus Diabetikum dapat dicegah.
\end{abstract}

Kata Kunci : Perilaku, Diabetes Melitus, Ulkus Diabetikum

\section{PENDAHULUAN}

Sebagai dampak positif pembangunan yang dilaksanakan oleh pemerintah, pola penyakit di Indonesia mulai mengalami pergeseran yang cukup meyakinkan. Penyakit infeksi dan kekurangan gizi berangsur turun, di lain pihak penyakit menahun yang disebabkan oleh penyakit degeneratif, di antaranya diabetes meningkat dengan tajam. Perubahan pola penyakit itu diduga ada hubungannya dengan cara hidup yang berubah (Sudoyo, 2007).

Diabetes merupakan gangguan metabolisme (Metabolic Syndrome) dari distribusi gula oleh tubuh. Penderita Diabetes tidak bisa memproduksi insulin dalam jumlah cukup, atau tubuh tak mampu menggunakan insulin secara efektif sehingga terjadilah kelebihan gula di dalam darah. Kelebihan gula yang kronis di dalam darah (hiperglikemia) ini menjadi racun bagi tubuh. Sebagai glukosa yang tertahan di dalam darah itu melimpah ke sistem urin untuk dibuang melalui urin. Air kencing penderita Diabetes yang mengandung gula dalam kadar tinggi tersebut menarik bagi semut, karena itulah gejala ini disebut juga gejala kencing manis (Vitahealth, 2006).

Di antara penyakit degeneratif, Diabetes adalah salah satu di antara penyakit tidak menular yang akan meningkat jumlahnya di masa mendatang. Diabetes telah menjadi penyebab kematian terbesar keempat di dunia. Setiap tahunnya ada 3,2 juta kematian yang disebabkan langsung oleh Diabetes. Itu berarti ada satu orang per 10 detik atau 6 orang per menit yang meninggal akibat penyakit yang berkaitan dengan Diabetes. Di Amerika yang sudah maju sekalipun, angka kematian akibat Diabetes bisa mencapai 200.000 orang per tahun (Tandra, 2008).

Menurut Organisasi Kesehatan Dunia (WHO) pada tahun 2000 dalam Waluyo (2009), bahwa ada sekitar 171 juta penduduk dunia menderita Diabetes. Sekitar $60 \%$ berada di Asia. Sedangkan dalam buku Soegondo (2008), menurut WHO pada Tahun 2003 terdapat lebih dari 200 juta orang dengan Diabetes di dunia. Angka ini akan bertambah menjadi 333 juta orang di tahun 2025.

Diabetes juga telah masuk dalam daftar "Penyakit Asia". Tahun 2003 saja diperkirakan 89 juta penduduk 
Asia menderita Diabetes. Tercatat 4 dari 5 negara di dunia dengan jumlah penderita Diabetes terbesar di Asia yaitu : India (32,7 juta penderita), RRC (22,6 juta penderita), Pakistan (8,8 juta penderita), dan Jepang (7,1 juta penderita). Angka penderita Diabetes yang didapatkan di Asia Tenggara adalah: Singapura 10,4\% (1992), Thailand 11,9\% (1995), Malaysia 8\% lebih (1997), dan Indonesia 5,7\% (1992). (Tandra, 2008).

Menurut data WHO, Indonesia menempati urutan ke-4 terbesar dalam jumlah penderita Diabetes Melitus di Asia Tenggara. Pada tahun 2000 yang lalu saja, terdapat sekitar 5,6 juta penduduk Indonesia yang mengidap Diabetes Melitus. Namun, pada tahun 2006 diperkirakan jumlah penderita Diabetes Melitus di Indonesia meningkat tajam 14 juta orang, dimana baru $50 \%$ yang sadar mengidapnya dan di antara mereka baru sekitar 30\% yang datang berobat teratur (Badawi, 2009).

Data yang diperoleh peneliti dari Medical Record RSUP H. Adam Malik Medan didapatkan bahwa jumlah penderita Diabetes Melitus yang dirawat inap dari bulan Januari sampai dengan bulan Desember tahun 2014 berjumlah 213 orang. Sedangkan jumlah penderita Diabetes Melitus yang dirawat inap dari bulan November 2014 sampai dengan bulan Januari tahun 2015 mencapai 55 orang.

Ulkus Diabetikum adalah adanya tukak atau borok dan atau kerusakan jaringan dalam, berhubungan dengan kelainan saraf dan pembuluh darah pada tungkai bawah (Adji, 2007).

Menurut penelitian klinik dari beberapa rumah sakit melaporkan prevalensi kaki diabetik di Indonesia khususnya Jakarta 32,9\% menempati urutan pertama, sedangkan urutan di bawahnya adalah Surabaya 27,6\%, Palembang 25,4\%, Ujung Pandang 20,6\% dan Semarang 17,3\% dari seluruh penderita Diabetes Mellitus yang dirawat di rumah sakit .

Gejala dan komplikasi kronis dapat dihindari dengan penanganan yang tepat dan teratur. Karena itu diabetisi (penderita Diabetes) harus mengenal penyakitnya dengan baik, sebab dia sendiri yang harus melaksanakan perawatannya sehari-hari (Soegondo 2008). Sayangnya diperkirakan setengah penderita Diabetes tidak melakukan diagnosis. Penyakit mulai diperhatikan benar-benar ketika seseorang sudah mulai mengalami kerusakan yang bisa dirasakannya. Seorang penderita Diabetes bisa saja menderita kebutaan, luka pada kaki atau kelainan dalam aktivitas berjalan (sulit berjalan atau tampak pincang) (Tjahajadi, 2010).

Penelitian ini bertujuan untuk mengetahui bagaimana hubungan perilaku pasien dalam perawatan diabetes melitus dengan ulkus diabetikum pada pasien diabetes melitus di Ruang Rindu A1 dan A2 di RSUP. H. Adam Malik Medan Tahun 2015.

\section{METODE PENELITIAN}

Penelitian ini merupakan jenis penelitian kuantitatif yang bersifat deskriptif analitik dengan menggunakan desain Cross Sectional berupa rancangan penelitian yang menekankan waktu pengukuran/observasi data variabel independen dan dependen hanya satu kali pada satu saat (Nursalam, 2009). Penelitian ini dilakukan di Ruang Rindu A1 dan A2 RSUP. H. Adam Malik Medan, sedangkan waktu penelitian dilaksanakan mulai bulan November 2014 s/d Januari tahun 2015. Populasi dalam penelitian adalah seluruh pasien Diabetes Melitus yang dirawat di Ruang Rindu A1 dan A2 RSUP. H. Adam Malik Medan Tahun 2015. Penentuan besar populasi dalam penelitian ini adalah berdasarkan jumlah pasien Diabetes Melitus yang dirawat bulan November 2014 s/d Januari 2015 sebanyak 55 orang dengan sampel sebesar 33 orang.

Data yang diperoleh meliputi data primer yang dikumpulkan langsung dari pasien, meliputi: pengetahuan, sikap, tindakan pasien dalam perawatan Diabetes Melitus, dan kejadian ulkus diabetikum. Dan data sekunder dikumpulkan dari Medical Record meliputi prevalensi penderita Diabetes yang dirawat di Ruang Rindu A1 dan A2 RSUP H. Adam Malik Medan. Data dianalisis secara univariat untuk mengetahui hasil distribusi dan persentase dari setiap variabel dan bivariat untuk menganalisa hubungan variabel independen dan variabel dependen dengan menggunakan uji chi-square, serta analisis multivariat untuk melihat hubungan antara semua variabel independen dengan variabel dependen pada waktu yang bersamaan dengan menggunakan uji Regresi Logistik Ganda.

\section{HASIL PENELITIAN DAN PEMBAHASAN}

\section{Analisis Univariat}

Dari hasil analisis data diketahui pengetahuan responden tentang perawatan diabetes melitus mayoritas cukup yaitu sebanyak 14 orang $(42,4 \%)$, baik yaitu sebanyak 10 orang $(30,3 \%)$ dan kurang sebanyak 9 orang $(27,3 \%)$. Berdasarkan sikap responden dalam perawatan diabetes melitus diketahui mayoritas positif yaitu sebanyak 19 orang $(57,6 \%)$ dan negatif sebanyak 14 orang $(42,4 \%)$. Berdasarkan tindakan responden dalam perawatan diabetes melitus tidak jauh berbeda yaitu sebanyak 17 orang $(51,5 \%)$ melakukan tindakan dengan baik dan sebanyak 16 orang $(48, \%)$ melakukan tindakan dengan tidak baik. Berdasarkan ulkus diabetikum responden, sebanyak 18 orang $(54,5 \%)$ tidak terjadi ulkus diabetikum dan sebanyak 15 orang $(45,5 \%)$ terjadi ulkus diabetikum.

\section{Analisis Bivariat}

Dari hasil analisis bivariat antara variabel independen (pengetahuan, sikap, tindakan) dengan variabel dependen (Ulkus Diabetikum) dengan menggunakan uji Chi Square, diperoleh hasil sebagai berikut :

1. Hubungan Pengetahuan responden DM dengan Ulkus Diabetikum

Dari 10 responden dengan pengetahuan baik, sebanyak 8 orang $(80 \%)$ tidak terjadi ulkus diabetikum dan hanya 2 orang $(20 \%)$ terjadi ulkus diabetikum. Dari 14 responden dengan 
pengetahuan baik sebanyak 8 orang $(57,1 \%)$ tidak terjadi ulkus diabetikum tetapi 6 orang $(42,9 \%)$ terjadi ulkus diabetikum. Dan dari 9 responden dengan pengetahuan kurang sebanyak 2 orang $(22,2 \%)$ tidak terjadi ulkus diabetikum dan sebanyak 7 orang $(77,8 \%)$ terjadi ulkus diabetikum. Dari hasil uji Chi Square (Pearson Chi Square) didapatkan $p$ value $=0,040(\mathrm{p}<0,05)$, sehingga Ha diterima dan Ho ditolak yang berarti ada hubungan yang signifikan antara pengetahuan pasien tentang perawatan Diabetes Melitus dengan Ulkus Diabetikum.

2. Hubungan Sikap responden DM dengan Ulkus Diabetikum

Dari 19 responden dengan sikap positif, sebanyak 14 orang $(73,7 \%)$ tidak terjadi ulkus diabetikum dan hanya 5 orang $(26,3 \%)$ terjadi ulkus diabetikum. Dan dari 14 responden dengan sikap negatif, sebanyak 4 orang $(28,6 \%)$ tidak terjadi ulkus diabetikum tetapi sebanyak 10 orang $(71,4 \%)$ terjadi ulkus diabetikum. Dari hasil uji Chi Square (Pearson Chi Square) didapatkan $p$ value $=0,027(\mathrm{p}<0,05)$, sehingga Ha diterima dan Ho ditolak yang berarti ada hubungan yang signifikan antara sikap pasien tentang perawatan Diabetes Melitus dengan Ulkus Diabetikum.

3. Hubungan Tindakan responden DM dengan Ulkus Diabetikum

Dari 17 responden dengan tindakan baik, sebanyak 13 orang $(76,5 \%)$ tidak terjadi ulkus diabetikum dan hanya 4 orang $(23,5 \%)$ terjadi ulkus diabetikum. Dan dari 16 responden dengan tindakan tidak baik, sebanyak 5 orang $(31,3 \%)$ tidak terjadi ulkus diabetikum tetapi sebanyak 11 orang $(68,8 \%)$ terjadi ulkus diabetikum. Dari hasil uji Chi Square (Pearson Chi Square) didapatkan $p$ value $=0,024(\mathrm{p}<0,05)$, sehingga Ha diterima dan Ho ditolak yang berarti ada hubungan yang signifikan antara tindakan pasien tentang perawatan Diabetes Melitus dengan Ulkus Diabetikum.

\section{Multivariat}

Tahapan analisis multivariat diawali dengan pemilihan variabel kandidat dengan pembuatan model dan uji interaksi dengan melakukan analisis bivariat yang menggunakan uji Regresi Logistik Sederhana

Berdasarkan hasil analisis data diketahui bahwa semua variabel memiliki $p$ value $<0,25$ dengan perincian pengetahuan memiliki $p$ value $0,033<0,25$, sikap memiliki $p$ value $0,009<0,25$, dan tindakan memiliki $p$ value $0,008<0,25$. Dengan demikian ketiga variabel tersebut layak masuk ke dalam analisis multivariat.

Berdasarkan pengujian Regresi Logistik Ganda variabel pengetahuan memiliki $p$ value $0,216>0,05$, variabel sikap memiliki $p$ value $0,049<0,05$, dan variabel tindakan memiliki $p$ value $0,079>0,05$. Dengan demikian variabel pengetahuan dikeluarkan dari model multivariat karena memiliki $p$ value terbesar. Sedangkan variabel sikap dan tindakan masuk ke dalam model multivariat selanjutnya.

Berdasarkan pengujian Regresi Logistik Ganda sikap memiliki $p$ value $0,039<0,05$ dengan nilai OR sebesar 5,868 (Perubahan OR 8,46\% < 10\%) sedangkan tindakan memiliki $p$ value $0,035<0,05$ dengan nilai OR sebesar 6,024 (Perubahan OR 0,97\% < $10 \%$ ) dan merupakan OR terbesar dibandingkan variabel lainnya setelah pembuatan model multivariat selesai. Dengan demikian dapat disimpulkan bahwa variabel tindakan merupakan satu-satunya variabel yang paling dominan berhubungan dengan ulkus diabetikum.

\section{PEMBAHASAN}

\section{Hubungan Pengetahuan Pasien tentang Perawatan Diabetes Melitus dengan Ulkus Diabetikum pada Pasien Diabetes Melitus}

Berdasarkan penelitian yang dilakukan diketahui bahwa pengetahuan memiliki hubungan yang bermakna dengan kejadian ulkus diabetikum dengan perincian dari hasil analisis univariat didapatkan bahwa mayoritas responden yang dirawat di Ruang Rindu A1 dan A2 RSUP H. Adam Malik Medan Tahun 2015 memiliki pengetahuan yang cukup tentang perawatan Diabetes Melitus yaitu sebanyak 14 orang $(42,4 \%)$.

Dari hasil analisis bivariat dengan menggunakan uji Chi Square (Pearson Chi Square) diperoleh $p$ value $=0,040<\alpha=0,05$ sehingga Ha diterima dan Ho ditolak yang berarti ada hubungan yang signifikan antara pengetahuan pasien tentang perawatan Diabetes Melitus dengan Ulkus Diabetikum dimana responden yang memiliki pengetahuan baik mayoritas tidak mengalami Ulkus Diabetikum yaitu sebanyak 8 orang (80\%), responden yang memiliki pengetahuan cukup mayoritas tidak mengalami Ulkus Diabetikum yaitu sebanyak 8 orang $(57,1 \%)$, sedangkan responden yang memiliki pengetahuan kurang mayoritas mengalami Ulkus Diabetikum yaitu sebanyak 7 orang $(77,8 \%)$

Hasil analisis multivariat dengan menggunakan uji Regresi Logistik Ganda didapatkan bahwa nilai OR dari variabel pengetahuan (1) adalah 0,796 artinya pasien Diabetes Melitus yang memiliki pengetahuan cukup memiliki resiko mengalami ulkus diabetikum sebesar 0,796 kali lebih tinggi dibandingkan dengan pasien Diabetes Melitus yang memiliki pengetahuan baik setelah dikontrol variabel sikap dan tindakan. Sedangkan nilai OR dari variabel pengetahuan (2) adalah 5,828 artinya pasien Diabetes Melitus yang memiliki pengetahuan kurang memiliki resiko mengalami Ulkus Diabetikum sebesar 5,828 kali lebih tinggi dibandingkan dengan pasien Diabetes Melitus yang memiliki pengetahuan baik setelah dikontrol variabel sikap dan tindakan.

Hasil penelitian ini sesuai dengan penelitian yang dilakukan oleh Daniati (2008) di RSUD Dr. M.Yunus Bengkulu bahwa terdapat hubungan antara pengetahuan dengan kejadian ulkus diabetikum pada pasien Diabetes Melitus dimana 53,12\% pasien 
Diabetes Melitus yang berpengetahuan baik tidak mengalami ulkus diabetikum.

Menurut asumsi peneliti, semakin tingginya angka kejadian Diabetes Melitus dewasa ini menyebabkan penyakit ini mendapat perhatian masyarakat terutama para penderitanya. Hal ini juga disebabkan oleh karena penyakit ini sangat bergantung pada penderitanya sendiri. Pada saat peneliti melakukan penelitian didapatkan bahwa sebagian besar responden merupakan pasien lama yang pernah dirawat di pelayanan kesehatan dengan penyakit yang sama sehingga telah mendapat cukup informasi mengenai penyakitnya.

\section{Hubungan Sikap Pasien dalam Perawatan Diabetes Melitus dengan Ulkus Diabetikum pada Pasien Diabetes Melitus}

Berdasarkan hasil penelitian yang dilakukan bahwa sikap pasien dalam perawatan Diabetes Melitus memiliki hubungan yang bermakna dengan Ulkus Diabetikum dengan perincian dari hasil analisis univariat didapatkan bahwa mayoritas responden yang dirawat di Ruang Rindu A1 dan A2 RSUP H. Adam Malik Medan Tahun 2015 memiliki sikap yang positif dalam perawatan Diabetes Melitus yaitu sebanyak 19 orang $(57,6 \%)$.

Dari hasil analisis bivariat dengan menggunakan uji Chi Square Square (Continuity Correction) diperoleh $p$ value $=0,027<\alpha=0,05$ sehingga $\mathrm{Ha}$ diterima dan Ho ditolak yang berarti ada hubungan yang signifikan antara sikap pasien dalam perawatan Diabetes Melitus dengan Ulkus Diabetikum dimana responden yang memiliki sikap positif mayoritas tidak mengalami Ulkus Diabetikum yaitu sebanyak 14 orang $(73,7 \%)$, sedangkan responden yang memiliki sikap negatif mayoritas mengalami ulkus diabetikum yaitu sebanyak 10 orang $(71,4 \%)$.

Hasil analisis multivariat dengan menggunakan uji Regresi Logistik Ganda didapatkan bahwa nilai OR dari variabel sikap adalah 5,868 artinya pasien Diabetes Melitus yang memiliki sikap negatif memiliki resiko mengalami Ulkus Diabetikum sebesar 5,868 kali lebih tinggi dibandingkan dengan pasien Diabetes Melitus yang memiliki sikap positif setelah dikontrol variabel tindakan.

Hasil penelitian ini sesuai dengan pendapat Notoatmodjo (2010) bahwa sikap merupakan domain penting dari perilaku seseorang yang belum merupakan suatu tindakan, akan tetapi merupakan predisposisi tindakan suatu perilaku.

Menurut asumsi peneliti, penyakit Diabetes Melitus sangat menuntut sikap positif dari penderitanya dikarenakan penyakit ini merupakan salah satu penyakit yang sangat dipengaruhi oleh gaya hidup seperti pola makan dan olah raga. Sebagian besar responden dalam penelitian telah hidup bersama Diabetes dalam waktu yang cukup lama, sehingga sudah cukup mengenal penyakit ini dengan baik dan juga menyikapinya dengan positif walaupun masih ada sebagian pasien yang kurang kooperatif dengan program perawatan. Jika penderita Diabetes Melitus dapat menyikapinya dengan positif maka resiko komplikasi seperti Ulkus Diabetikum tidak akan terjadi.

\section{Hubungan Tindakan Pasien dalam Perawatan Diabetes Melitus dengan Ulkus Diabetikum pada Pasien Diabetes Melitus}

Berdasarkan hasil analisis bivariat dengan menggunakan uji Chi Square Square (Continuity Correction) diperoleh nilai $p$ value $=0,024<\alpha=0,05$ sehingga Ha diterima dan Ho ditolak yang berarti ada hubungan yang signifikan antara tindakan pasien dalam perawatan Diabetes Melitus dengan Ulkus Diabetikum dimana responden yang memiliki tindakan baik mayoritas tidak mengalami ulkus diabetikum yaitu sebanyak 13 orang $(76,5 \%)$, sedangkan responden yang memiliki tindakan tidak baik mayoritas mengalami ulkus diabetikum yaitu sebanyak 11 orang $(68,8 \%)$.

Dari hasil analisis multivariat dengan menggunakan uji Regresi Logistik Ganda didapatkan bahwa nilai OR dari variabel tindakan adalah 6,024 artinya pasien Diabetes Melitus yang memiliki tindakan tidak baik memiliki resiko sebesar 6,024 kali lebih tinggi mengalami Ulkus Diabetikum dibandingkan dengan pasien Diabetes Melitus yang memiliki tindakan tidak baik setelah dikontrol variabel sikap. Dari hasil akhir analisis multivariat dapat disimpulkan bahwa variabel tindakan merupakan variabel yang paling dominan berhubungan dengan kejadian Ulkus Diabetikum karena memiliki nilai OR paling besar dibandingkan variabel pengetahuan dan sikap.

Hasil penelitian ini sejalan dengan pendapat Notoatmodjo (2010) bahwa tindakan merupakan hal apa yang dilakukan oleh responden terkait dengan kesehatan (pencegahan penyakit), cara peningkatan kesehatan, cara memperoleh pengobatan yang tepat dan sebagainya. Setelah sesorang mengetahui stimulus atau objek kesehatan, kemudian mengadakan penilaian atau pendapat terhadap apa yang diketahui, proses selanjutnya diharapkan ia akan melaksanakan atau mempraktikkan apa yang diketahui atau dinilai baik. Inilah yang disebut praktik atau wujud dari perilaku kesehatan.

Menurut asumsi peneliti, keberadaan variabel tindakan sebagai domain perilaku yang paling dominan berhubungan dengan ulkus diabetikum dikarenakan tindakan merupakan wujud dari perilaku. Pengetahuan dan sikap merupakan domain penting dalam membentuk perilaku namun tindakanlah yang menjadi faktor penentu dari akibat perilaku tersebut. Sebagian besar responden telah berupaya dengan baik dalam mengendalikan penyakit yang dideritanya sehingga Ulkus Diabetikum dapat dicegah namun sebagian memiliki tindakan yang tidak baik disebabkan kurang pengetahuan dan perhatian terhadap penyakit yang diderita sehingga menyebabkan terjadinya Ulkus Diabetikum. 


\section{KESIMPULAN DAN SARAN}

\section{Kesimpulan}

1. Dari hasil penelitian berdasarkan analisis univariat didapatkan bahwa mayoritas pasien Diabetes Melitus yang dirawat di Ruang Rindu A1 dan A2 RSUP H. Adam Malik Medan Tahun 2015 memiliki pengetahuan yang cukup tentang perawatan Diabetes Melitus (42,4\%).

2. Dari hasil penelitian berdasarkan analisis univariat didapatkan bahwa mayoritas pasien Diabetes Melitus yang dirawat di Ruang Rindu A1 dan A2 RSUP H. Adam Malik Medan Tahun 2015 memiliki sikap yang positif dalam perawatan Diabetes Melitus (57,6\%).

3. Dari hasil penelitian berdasarkan analisis univariat didapatkan bahwa mayoritas pasien Diabetes Melitus yang dirawat di Ruang Rindu A1 dan A2 RSUP H. Adam Malik Medan Tahun 2015 memiliki tindakan yang baik perawatan Diabetes Melitus (51,5\%).

4. Dari hasil penelitian berdasarkan analisis univariat didapatkan bahwa mayoritas pasien Diabetes Melitus yang dirawat di Ruang Rindu A1 dan A2 RSUP H. Adam Malik Medan Tahun 2015 tidak mengalami ulkus diabetikum $(54,5 \%)$.

5. Dari hasil penelitian berdasarkan analisis bivariat dengan menggunakan uji Chi Square dapat disimpulkan bahwa ada hubungan antara pengetahuan dengan Ulkus Diabetikum pada pasien Diabetes Melitus yang dirawat di Ruang Rindu A1 dan A2 RSUP H. Adam Malik Medan Tahun 2015 ( $p$ value $=0,040<\alpha=0,05$ ).

6. Dari hasil penelitian berdasarkan analisis bivariat dengan menggunakan uji Chi Square dapat disimpulkan bahwa ada hubungan antara sikap dengan Ulkus Diabetikum pada pasien Diabetes Melitus yang dirawat di Ruang Rindu A1 dan A2 RSUP H. Adam Malik Medan Tahun 2015 ( $p$ value $=0,027<\alpha=0,05)$.

7. Dari hasil penelitian berdasarkan analisis bivariat dengan menggunakan uji Chi Square dapat disimpulkan bahwa ada hubungan antara tindakan dengan Ulkus Diabetikum pada pasien Diabetes Melitus yang dirawat di Ruang Rindu A1 dan A2 RSUP H. Adam Malik Medan Tahun 2015 ( $p$ value $=0,024<\alpha=0,05$ ).

8. Dari hasil penelitian berdasarkan analisis multivariat dengan menggunakan uji Regresi Logistik Ganda dapat disimpulkan bahwa domain perilku yang paling dominan berhubungan terhadap kejadian Ulkus Diabetikum pada pasien Diabetes Melitus yang dirawat di Ruang Rindu A1 dan A2 RSUP H. Adam Malik Medan Tahun 2015 adalah tindakan dengan nilai OR sebesar 6,024.

\section{Saran}

1. Kepada pihak RSUP H. Adam Malik Medan khususnya di Ruang Rindu A1 dan A2 agar lebih meningkatkan pelayanan keperawatan dan pelaksanaan asuhan keperawatan khususnya dalam meningkatkan perilaku kesehatan pasien Diabetes Melitus atau mengubah perilaku negatif pasien Diabetes Melitus menjadi positif dalam hal perawatan Diabetes Melitus melalui kerjasama dengan keluarga sebagai pendamping pasien yang diharapkan memberikan dukungan pada pasien dalam perawatan penyakit Diabetes Melitus.

2. Kepada institusi pendidikan khususnya Jurusan Keperawatan agar menjadi masukan dalam menerapkan pengetahuan dan mendalami penelitian selanjutnya tentang hubungan antara perilaku pasien dalam perawatan Diabetes Melitus dengan Ulkus Diabetikum pada Pasien Diabetes Melitus.

3. Kepada pasien diharapkan supaya mempertahankan perilaku yang mendukung perawatan Diabetes Melitus sehingga kejadian Ulkus Diabetikum dapat dicegah karena penyakit Diabetes Melitus sangat tergantung dari perilaku kesehatan penderitanya.

4. Kepada peneliti lain agar meneliti lebih lanjut mengenai faktor lain yang mempengaruhi kejadian Ulkus Diabetikum pada pasien Diabetes Melitus atau melakukan tindak lanjut dari hasil penelitian yang telah ada sehingga hasil penelitian ini dapat bermanfaat khususnya bagi penderita Diabetes Melitus

\section{DAFTAR PUSTAKA}

Badawi, Hasan, 2009, Melawan dan Mencegah Diabetes, Araska Printika, Yogyakarta.

Notoatmodjo, Soekidjo, 2005, Metodologi Penelitian Kesehatan, Rineka Cipta, Jakarta.

-,2010, Ilmu Perilaku Kesehatan, Rineka Cipta, Jakarta.

Nurhasan, 2002, Kiat Melawan Penyakit, Pustaka Pelajar, Jogjakarta

Nursalam, 2009, Konsep dan Penerapan Metodologi Penelitian Ilmu Keperawatan Edisi 2, Salemba Medika, Jakarta

Soegondo, Sidartawan, 2008, Hidup Secara Mandiri dengan Diabetes Melitus, Kencing Manis, Sakit Gula, Balai Penerbit Fakultas Kedokteran Universitas Indonesia, Jakarta.

Sudoyo, Aru W, 2007, Buku Ajar Ilmu Penyakit Dalam, Balai Penerbit Fakultas Kedokteran Universitas Indonesia, Jakarta

Tandra, Hans, 2008, Segala Sesuatu yang Harus Anda Ketahui Tentang Diabetes, PT Gramedia Pustaka Utama, Jakarta.

Tjahdadi, Vicynthia, 2010, Mengenal, Mencegah, Mengatasi Silent Killer Diabetes, Pustaka Widyamara, Semarang.

Vitahealth, 2006, Diabetes, PT Gramedia Pustaka Utama, Jakarta.

Waluyo, Srikandi, 2009, 100 Qustions \& Answers Diabetes, PT Elex Media Komputindo, Jakarta. 